\title{
SENTIDOS DE INTEGRAÇÃO CURRICULAR NAS REFORMAS RECENTES DO ENSINO MÉDIO: ENTRE AS ÁREAS DO CONHECIMENTO E A ORGANIZAÇÃO DISCIPLINAR
}

\author{
Heloize da Cunha CHARRET ${ }^{i}$ \\ Marcia Serra FERREIRA ${ }^{\text {ii }}$
}

\begin{abstract}
RESUMO
O trabalho investiga os sentidos de integração curricular produzidos, disputados e fixados no tempo presente, focalizando as políticas para o Ensino Médio no Brasil e, em particular, para a área de Ciências da Natureza e suas Tecnologias. São investigados documentos oficiais das reformas recentes para esse nível de ensino: os Parâmetros Curriculares Nacionais, a Reforma do Ensino Médio e a Base Nacional Comum Curricular. A ideia foi analisar as regulações e efeitos dessas políticas, tomando como referência um histórico e importante embate que se explicita e ganha força entre as áreas do conhecimento e as disciplinas escolares. No diálogo com Michel Foucault, curriculistas (como Thomas Popkewitz e Stephen Ball) e historiadores (Reinhart Koselleck, por exemplo), é assumida uma abordagem discursiva para a produção de uma História do Currículo do Presente. Tomando a interdisciplinaridade como o significado hegemônico que a integração curricular veio assumindo historicamente, se analisam os deslocamentos do discurso reformista na direção das áreas do conhecimento, ainda que regulado pelas regras e padrões da organização disciplinar. Nesse movimento, o termo disciplina escolar vai deixando de ser enunciado, em um movimento que desloca os sentidos de integração curricular no diálogo com os componentes curriculares. As noções de competências e habilidades vão se transformando em elementos de adjetivação do conhecimento disciplinarizado, produzindo efeitos no modo como passamos a pensar a 'validade' daquilo que ensinamos e aprendemos no ensino médio, assim como os nossos papéis como professores e estudantes nesse nível da educação básica.
\end{abstract}

PALAVRAS-CHAVE: História do Currículo; Integração Curricular; Áreas do Conhecimento; Disciplinas Escolares.

\section{MEANINGS OF CURRICULAR INTEGRATION IN RECENT HIGH SCHOOL REFORMS: BETWEEN KNOWLEDGE AREAS AND THE DISCIPLINARY ORGANIZATION}

\section{ABSTRACT}

\footnotetext{
${ }^{\text {i }}$ Professora de Física no ensino médio, concluiu os seus estudos de doutorado no Programa de Pós-Graduação em Educação da Universidade Federal do Rio de Janeiro (PPGE/UFRJ) em 2019, sob a supervisão da segunda autora. É pesquisadora associada ao Grupo de Estudos em História do Currículo, no âmbito do NEC/UFRJ. Email: heloizecharret@gmail.com.

ii Professora Associada da Faculdade de Educação da UFRJ, atuando na Licenciatura em Ciências Biológicas e no PPGE. É bolsista de produtividade (PQ2/CNPq) e Cientista do Estado do Rio de Janeiro (CNE/Faperj). Realizou estudos de pós-doutoramento na Unicamp (2016/2017) e como Fulbright Visiting Scholar na UWMadison, USA (2017). Coordena o Grupo de Estudos em História do Currículo, no âmbito do NEC/UFRJ. Email: marciaserraferreira@gmail.com.
} 
In this paper we analyze the meanings of curriculum integration produced, disputed and fixed in the present time, focusing the High School policies in Brazil, in particular for the area of Natural Sciences and its Technologies. Official documents were investigated: the National Curriculum Parameters, the High School Reform and the Common Curriculum National Base. The idea was to analyze the regulations and effects of these policies, taking as reference a historical and important clash that is explicit and gains strength between the areas of knowledge and the school subjects. In dialogue with Michel Foucault, curriculists (such as Thomas Popkewitz and Stephen Ball) and historians (Reinhart Koselleck, for example), a discursive approach is taken to produce a Curriculum History to the Present. Taking interdisciplinarity as the hegemonic meaning that curriculum integration has historically assumed, we analyze the displacements of reformist discourse towards the areas of knowledge, even though regulated by the rules and standards of disciplinary organization. In this movement, the term school subject is no longer stated, in a movement that shifts the senses of curriculum integration in the dialogue with the curriculum components. The notions of competences and skills become elements of the adjectivation of disciplined knowledge, producing effects on the way we come to think about the 'validity' of what we teach and learn in high school, as well as our roles as teachers and students at this level of schooling.

KEYWORDS: Curriculum History; Curriculum Integration; Knowledge Areas; School Subjects.

\title{
SENTIDOS PARA LA INTEGRACIÓN CURRICULAR EN REFORMAS RECIENTES DE LA ESCUELA SECUNDARIA: ENTRE ÁREAS DE CONOCIMIENTO Y LA ORGANIZACIÓN DISCIPLINARIA
}

\begin{abstract}
RESUMEN
Este trabajo investiga los significados de integración curricular producidos, disputados y arreglados en la actualidad, enfocándose en las políticas para la escuela secundaria en Brasil y, en particular, para el área de Ciencias de la Naturaleza y sus Tecnologías. Se investigan los documentos oficiales de las reformas recientes para este nivel de educación: los Parámetros Curriculares Nacionales, la Reforma de la Escuela Secundaria y la Base Nacional Común Curricular. La idea era analizar las regulaciones y los efectos de estas políticas, tomando como referencia un choque histórico e importante que es explícito y gana fuerza entre las áreas de conocimiento y las materias escolares. En diálogo con Michel Foucault, investigadores em el area curricular (como Thomas Popkewitz y Stephen Ball) e historiadores (Reinhart Koselleck, por ejemplo), se adopta un enfoque discursivo para producir una Historia del Currículo do Presente. Tomando la interdisciplinariedad como el significado hegemónico que la integración curricular ha asumido históricamente, analizamos los desplazamientos del discurso reformista hacia las áreas del conocimiento, aunque estén regulados por las reglas y estándares de la organización disciplinaria. En este movimiento, el término materia escolar ya no se establece, en un movimiento que cambia los sentidos de la integración curricular en el diálogo con los componentes curriculares. Las nociones de competencias y habilidades se convierten en elementos del adjetivo de conocimiento disciplinado, produciendo efectos en la forma en que pensamos sobre la 'validez' de lo que enseñamos y aprendemos en la escuela secundaria, así como nuestros roles como maestros y estudiantes en este nível de la Educación Básica.
\end{abstract}

PALABRAS CLAVE: Historia del Currículo; Integración curricular; Áreas de Conocimiento; Materias Escolares.

\section{INTRODUÇÃO}


Neste artigo, analisamos os sentidos de integração curricular que vêm sendo produzidos, disputados e fixados no tempo presente, focalizando as políticas para o Ensino Médio no Brasil e, em particular, para a área de Ciências da Natureza e suas Tecnologias. Para realizar essa tarefa, investigamos documentos oficiais que vieram sendo elaborados nas reformas recentes para esse nível de ensino: os Parâmetros Curriculares Nacionais (BRASIL, 1999); a Reforma do Ensino Médio, materializada na promulgação da Lei 13.415 (BRASIL, 2017); a Base Nacional Comum Curricular (BRASIL, 2018). A ideia foi investigar as regulações e efeitos dessas políticas de currículo, tomando como referência um histórico e importante embate que se explicita e ganha força entre as áreas do conhecimento e as disciplinas escolares. Afinal, a partir dos anos de 1990, nas reformas educacionais brasileiras, esse embate produziu efeitos que ora deslocam o conhecimento disciplinar de seu papel hegemônico, ora o reestabilizam.

Ele é parte de uma investigação de doutorado já concluída (CHARRET, 2019), elaborada no âmbito de projetos de pesquisa mais amplos ${ }^{1}$, que têm sido desenvolvidos no Grupo de Estudos em História do Currículo e que, em linhas gerais, se encontram voltados para a construção de uma abordagem discursiva para a realização desses estudos no (e do) presente (ver, por exemplo, FERREIRA, 2013 e 2015; FERREIRA \& SANTOS, 2017). Em articulação com as Políticas de Currículo (BOWE, BALL \& GOLD, 1992), vimos assumindo "os acontecimentos recentes como objetos privilegiados de investigação historiográfica" (FERREIRA \& SANTOS, 2017, p. 62), em um movimento que entende as reformas curriculares que emergem a partir dos anos de 1990 como parte das lutas políticas que produzem os conhecimentos e os sujeitos da educação no país. No diálogo com Koselleck (2014), percebemos os acontecimentos como estratos temporais que, apesar de possuírem emergências, durações e motivações distintas, estão presentes e atuando simultaneamente, constituindo o que pode ser nomeado de uma História do Currículo do Presente. É com tal entendimento que, na próxima seção, aprofundamos essa perspectiva teórico-metodológica por meio do que vimos nomeando de uma abordagem discursiva.

\section{UMA ABORDAGEM DISCURSIVA PARA A HISTÓRIA DO CURRÍCULO}


Nosso esforço por desenvolver uma abordagem discursiva para a constituição de uma História do Currículo do Presente na qual somos, ao mesmo tempo, investigadores e testemunhas, tem implicado na mobilização de outras perspectivas de temporalidade. Para essa tarefa, como já explicitado, temos utilizado o conceito de estratos do tempo de Koselleck (2014, p. 9), no qual a história se estabelece a partir de acontecimentos que não se sucedem ou se encadeiam em uma mera disposição cronológica, mas se depositam por meio de diferentes temporalidades, o que significa que "estão presentes e atuam simultaneamente". É importante destacar, no entanto, que encarar a deposição dos acontecimentos históricos em estratos não significa, como indica Santos (2017), escavar em busca de eventos 'encobertos' que precisariam ser 'desvelados' e/ou reinterpretados. Para esse autor, "diferentemente, é pensarmos que nessas diferentes camadas repousam práticas discursivas que conseguiram se condensar, e não outras, e que passaram a regular as condições de enunciação de determinadas verdades sobre uma dada área” (SANTOS, 2017, p. 91).

Além da temporalidade, outros conceitos importantes para escrutinar os acontecimentos históricos como estratos do tempo são os de espaços de experiência e horizontes de expectativa (KOSELLECK, 2006). Assumindo que esses dois conceitos se entrecruzam, permanecem e constituem o presente, com Koselleck (2006) 'remexemos' na seta do tempo e passamos a pensar no presente como o local onde a tensão entre passado e futuro se manifesta. É no presente, portanto, que se desdobram em projeções de futuro as aspirações e expectativas que são criadas a partir da memória e das experiências que se construíram no passado. No Grupo de Estudos em História do Currículo, temos operado com essa noção de historicidade, compreendendo as reformas recentes "equacionando tanto as tradições curriculares quanto os projetos de futuro" (FERREIRA \& SANTOS, 2017, p. 62). Afinal, de acordo com Santos (2017, p. 90), pensar nos termos propostos por Koselleck (2006 e 2014) de modo articulado com as formulações de Foucault (2012a):

[...] potencializa a metáfora da arqueologia, já que nos leva a pensar nos movimentos de deposição que possibilitaram o assentamento de certos enunciados, discursos, acontecimentos em tal ou qual tempo histórico. Tal assentamento, por sua vez, captura, nessa deposição, significados que, por fazerem parte de uma prática discursiva específica de um determinado tempo histórico, vão regular as condições de enunciação nos tempos históricos que vierem a sucedê-lo. Em outras palavras, ao fazer um estudo dessa envergadura, é como se estivéssemos a escavar e fossemos em busca daquilo que lá, nas camadas subjacentes, se sedimentou, passando a regular o que é possível de encontrarmos como enunciações no presente e, portanto, o que 
será possível encontrarmos no futuro (SANTOS, 2017, p. 90).

É com tal perspectiva que assumimos o recorte temporal aqui delineado - o período compreendido entre 1998/1999, quando as áreas do conhecimento emergem nas políticas públicas para o ensino médio, e 2018, quando a Base Nacional Comum Curricular para esse nível de ensino é publicada -, constituindo um arquivo de pesquisa que percebe a integração curricular sendo ressignificada em meio às lutas políticas que vieram se dando em torno da definição de áreas do conhecimento em meio à organização disciplinar. Investimos aqui na hipótese de que as disciplinas escolares são o elemento estabilizado na lógica do currículo do ensino médio, entrando em embate com a noção alternativa de áreas do conhecimento.

Nela, o currículo permanece sendo concebido como tradição inventada, utilizando expressão de Hobsbawm (apud GOODSON, 1995 e 1997), ainda que tais invenções sejam percebidas no âmbito do discurso. Além disso, as políticas de currículo são produzidas em variados contextos, em meio a jogos de saber e poder (BOWE, BALL \& GOLD, 1992). No diálogo com Foucault (2012a e 2012b) e alguns de seus interlocutores no campo do Currículo (FISCHER, 2012; POPKEWITZ, 1994, 1997 e 2001), o processo de desenvolvimento do currículo é percebido como uma prática discursiva (FOUCAULT, 2012a e 2012b) que é responsável por estabelecer mecanismos de regulação social. A escolha desse caminho teórico implica em focalizar os processos de transformação e mudança em meio às estabilidades curriculares, entendendo a inovação não como o rompimento com um passado a ser superado, mas como um movimento descontínuo no qual os embates se dão no âmbito do discurso, produzindo, de modo relacional, aquilo que definimos como 'novo' em meio ao que significamos como 'tradicional' (FERREIRA, 2005). Afinal, como já enunciado em Ferreira (2005), as inovações se tornam possíveis em meio às estabilidades constituídas no âmbito do currículo escolar.

Compreender o papel regulador da organização disciplinar no processo de estruturação das áreas do conhecimento significa assumir que, para identificar os sentidos de integração curricular enunciados no contexto do ensino médio, é importante analisar os deslocamentos produzidos pelas reformas recentes nas formas historicamente elaboradas de organização dos currículos. Para realizar essa tarefa, tomamos como referência o papel das comunidades disciplinares, conforme descritas por Goodson (1997), na produção dos enunciados que participam dos embates em torno das definições do que conta como 
conhecimento disciplinarizado. Assim, em produções anteriores (CHARRET \& FERREIRA, 2016, 2017a e 2017b; CHARRET, BRASIL \& FERREIRA, 2017 e 2018), analisando textos acadêmicos produzidos no âmbito dessas comunidades disciplinares, evidenciamos que a integração curricular vem sendo significada, predominantemente, como interdisciplinaridade. Nesse movimento, certas produções se apropriam de enunciados presentes nos documentos oficiais das reformas, argumentando que a interdisciplinaridade é uma metodologia indicada pelas políticas, uma vez que se propõe a tornar mais simples e/ou interessante o ensino de temáticas disciplinares. Tais enunciados reafirmam, mais uma vez, a hegemonia das disciplinas como forma de organização curricular para o ensino médio.

Entendendo que a constituição de uma área do conhecimento nomeada Ciências da Natureza traz outros enunciados para as lutas que são travadas no âmbito dessas comunidades, podendo, inclusive, constituir outros grupos, interessa-nos perceber como as disciplinas escolares passam a se movimentar no presente, regulando a organização dos currículos, ainda que impactadas por uma perda de prestígio para as áreas do conhecimento. Nesse contexto, a interdisciplinaridade atua como um discurso ambivalente que, ao reforçar a noção de integração curricular, contribui para a estabilidade da organização disciplinar. Afinal, para autoras como Mozena \& Ostermann (2014), a abordagem interdisciplinar apresenta uma alternativa que valoriza a possibilidade de integração entre variadas disciplinas no âmbito das áreas de conhecimento sem suprimir as especificidades de cada uma delas.

Assumimos que a análise aqui produzida requer uma abordagem que contemple os mecanismos dinâmicos em torno dos quais os processos de enunciação se estabelecem, levando em conta a multiplicidade de interesses que se articulam e os inúmeros conflitos que se estabelecem na constituição das políticas de currículo. Segundo Mainardes (2006), os autores Bowe, Ball \& Gold (1992), em sua abordagem do ciclo de políticas, oferecem uma perspectiva metodológica que pretende responder a essa demanda. Afinal, eles assumem que os estágios de formulação, documentação e implantação das políticas não são estanques e que os sentidos veiculados pelos textos políticos não são fixos, mas dependem de processos de interpretação e contestações nos diferentes espaços onde circulam. Isso significa assumir que nenhuma política é apenas 'aceita' ou 'recusada' em um processo vertical de imposição do Estado para as instituições e sujeitos da educação; ao invés disso, os autores propõem que, em variados contextos, a política é sempre interpretada e ressignificada, produzindo regulações e efeitos que não são controlados e/ou totalmente previsíveis pelo Estado. É com tal 
abordagem, portanto, que, na próxima seção, analisamos os sentidos de integração curricular que vieram sendo produzidos em meio a outros significantes que estruturam, historicamente, o ensino médio brasileiro, com destaque para as noções de disciplinas escolares e áreas do conhecimento.

\section{SENTIDOS DE INTEGRAÇÃO CURRICULAR: ENTRE AS DISCIPLINAS ESCOLARES E AS ÁREAS DO CONHECIMENTO}

Investigando os Parâmetros Curriculares Nacionais (BRASIL, 1999), a Reforma do Ensino Médio, materializada na promulgação da Lei 13.415 (BRASIL, 2017), e a Base Nacional Comum Curricular (BRASIL, 2018) em meio a outros textos nos quais as políticas de currículo vieram sendo 'reformadas', assumimos que o arquivo aqui mobilizado 'guarda' os embates que foram travados e que vieram produzindo, no tempo presente, os sentidos de integração curricular que participam da constituição das políticas do (e para o) ensino médio. Tal perspectiva, como sugere Fischer (2012), envolve as seguintes “atitudes metodológicas":

A primeira é compreender que nossas lutas (e pesquisas) sempre têm a ver com linguagem, já que estamos continuamente envolvidos com lutas discursivas; a segunda atitude é atentar para a ideia de que palavras e coisas dizem respeito a fatos e enunciados, que a rigor são 'raros', isto é, não são óbvios, estão para além das 'coisas dadas'; a terceira, que fatos e enunciados referem-se basicamente a práticas discursivas e não discursivas, as quais constituem matéria-prima de nossas investigações, (não importa em que campo se concentrem) e que dizem respeito sempre a relações de poder e a modos de constituição dos sujeitos individuais e sociais; finalmente, a atitude de entrega do pesquisador a modos de pensamento que aceitem o inesperado, especialmente aquilo que se diferencia do que ele próprio pensa (FISCHER, 2012, p. 100, grifos originais).

Em meio a tais "atitudes metodológicas", assumimos que as reformas não constituem movimentos de ruptura e/ou aperfeiçoamento nos quais um dispositivo apenas substitui outro no âmbito das práticas de escolarização. Diferentemente, elas constituem um interessante cenário no qual, de acordo com Popkewitz (1994, p. 205), torna-se possível entender "como regras e padrões particulares de verdade atravessam padrões institucionais particulares, não sendo redutíveis àqueles padrões". Tomando a organização disciplinar como um desses "padrões de verdade" que vieram produzindo, historicamente, a escolarização, investigamos os sentidos de integração curricular que vieram sendo forjados em meio à emergência da 
noção de áreas do conhecimento nas políticas do (e para o) ensino médio.

Analisamos as noções de áreas do conhecimento e disciplinas escolares como constituidoras de um par binário, no sentido proposto por Popkewitz (2001, p. 48, grifos originais), ou seja, como dois significantes que se associam estabelecendo "um contínuo de valores em que um lado das distinções é privilegiado, à medida que o conjunto cria o que é 'bom' e 'normal'”. Refletindo sobre esse par binário, é possível observar em um dos polos a 'tradição', frequentemente associada à organização disciplinar, enquanto no outro se fixa a 'inovação', que se articula à emergência das áreas de conhecimento. Tais significantes se constituem mutuamente, produzindo os conhecimentos e sujeitos da escolarização ao estabelecerem "regras e obrigações que organizam e disciplinam a forma como o mundo deve ser visto, sentido e como se deve agir e falar sobre ele" (POPKEWITZ, 1997, p. 22).

Nesse contexto, a intenção foi questionar não apenas as mudanças nos discursos das políticas, mas perceber as condições que possibilitaram que a integração curricular, muitas vezes enunciada como interdisciplinaridade, fosse conferindo legitimidade ao discurso reformista. Em tal movimento, evidenciamos o quanto o usual embate entre as áreas do conhecimento e as disciplinas escolares tem sido 'alimentado' por enunciados de integração curricular que aproximam as noções de conhecimento e de competências, outro enunciado frequente na retórica reformista, conforme se evidencia nos seguintes textos legais:

Considerando-se tal contexto, buscou-se construir novas alternativas de organização curricular para o ensino médio comprometidas, de um lado, com o novo significado do trabalho no contexto da globalização e, de outro, com o sujeito ativo, a pessoa humana que se apropriará desses conhecimentos para se aprimorar, como tal, no mundo do trabalho e na prática social (BRASIL, 1999, p. 30).

Na BNCC, competência é definida como a mobilização de conhecimentos (conceitos e procedimentos), habilidades (práticas, cognitivas e socioemocionais), atitudes e valores para resolver demandas complexas da vida cotidiana, do pleno exercício da cidadania e do mundo do trabalho (BRASIL, 2018, p. 8).

Na Educação Básica, a área de Ciências da Natureza deve contribuir com a construção de uma base de conhecimentos contextualizada, que prepare os estudantes para fazer julgamentos, tomar iniciativas, elaborar argumentos e apresentar proposições alternativas, bem como fazer uso criterioso de diversas tecnologias. O desenvolvimento dessas práticas e a interação com as demais áreas do conhecimento favorecem discussões sobre as implicações éticas, socioculturais, políticas e econômicas de temas relacionados às Ciências da Natureza (BRASIL, 2018, p. 537). 
Nos extratos anteriores, o conceito de competência emerge como um fator que positiva o conhecimento nos diferentes documentos oficiais ao longo de todo o período da reforma. Isso parece indicar que os sentidos de conhecimento, assim como dos estudantes projetados pelos textos das políticas, precisam ser percebidos como parte de um mesmo sistema de pensamento (POPKEWITZ, 2001) que possibilita a existência das reformas recentes, ao invés de percebê-los de modo antagônico à noção de competências. Assim, assumimos que os sentidos de integração curricular mobilizados pela reforma se associam a outros significados - como os de conhecimento e competência -, bem como as relações que estes estabelecem entre si, atravessando os embates entre as áreas do conhecimento e as disciplinas escolares.

Outro interessante exemplo de como a integração curricular foi sendo significada em meio a esses embates emerge na apresentação da estrutura curricular do ensino médio relativa à Base Nacional Comum Curricular (BRASIL, 2018, p. 32), na qual duas disciplinas escolares figuram com destaque - a Língua Portuguesa e a Matemática, essa última ocupando a posição ambivalente de disciplina e, simultaneamente, de área do conhecimento -, em meio a áreas do conhecimento que aparecem de forma mais genérica, isto é, sem a explicitação das disciplinas escolares que as compõem, como é o caso das Ciências da Natureza e suas Tecnologias. Na verdade, assumimos que a Base Nacional Comum Curricular é marcada por um processo de ressignificação das disciplinas escolares, um termo que, apesar de regular as políticas de currículo aqui analisadas, perde centralidade nessa proposta de organização curricular. No texto do (e para o) ensino médio, esse termo é enunciado pela primeira vez apenas na página 32 e apenas por meio de uma citação direta de outro documento, o Parecer CNE/CP 11/2009, ao destacar que a organização por áreas do conhecimento:

[...] não exclui necessariamente as disciplinas, com suas especificidades e saberes próprios historicamente construídos, mas, sim, implica o 'fortalecimento das relações' entre elas e a sua 'contextualização para apreensão e intervenção na realidade', requerendo trabalho conjugado e cooperativo dos seus professores no planejamento e na execução dos planos de ensino (BRASIL, 2009 apud BRASIL, 2017, p. 32, grifos adicionados).

Ainda que o texto mencione, por meio da citação direta anteriormente explicitada, o "fortalecimento das relações" entre as disciplinas escolares, esta serve para justificar uma outra estrutura curricular para o ensino médio. Tal estrutura, como já mencionado, mescla uma organização por áreas do conhecimento com a explícita presença da Língua Portuguesa 
como disciplina escolar e da Matemática, que ocupa, simultaneamente, as posições de disciplina escolar e de área do conhecimento. Ele prossegue hierarquizando disciplinas escolares e áreas do conhecimento ao defender a importância de um detalhamento das habilidades de Língua Portuguesa e a Matemática, que devem estar presentes em todo o ensino médio, versus uma flexibilidade das habilidades relativas aos demais "componentes curriculares". Observe como essa hierarquização é enunciada no texto legal:

Em função das determinações da Lei $n^{\circ} 13.415 / 2017$, são detalhadas as habilidades de Língua Portuguesa e Matemática, considerando que esses componentes curriculares devem ser oferecidos nos três anos do Ensino Médio. Ainda assim, para garantir aos sistemas de ensino e às escolas a construção de 'currículos e propostas pedagógicas flexíveis e adequados à sua realidade', essas habilidades são apresentadas sem indicação de seriação (BRASIL, 2017, p. 32, grifos nossos).

Como vimos, o trecho anterior insere o discurso da flexibilização e adequação curricular como um elemento central para que se possa entender a lógica aplicada à 'nova' organização curricular do ensino médio. Além disso, o significante “componentes curriculares" passa a ocupar a posição que antes era, majoritariamente, das disciplinas escolares, ressignificando esse termo. Afinal, agora as disciplinas escolares Língua Portuguesa e Matemática, ambas consagradas na tradição curricular brasileira, se tornam componentes curriculares. Ao afirmar que esses (e não outros) componentes curriculares devem ser oferecidos ao longo dos três anos, o texto já insere alguns outros sentidos para ambos quando comparados às antigas disciplinas escolares. Os outros componentes curriculares, inespecíficos porque não mencionados textualmente no texto legal, não possuem espaço semelhante determinado e/ou garantido nos currículos do ensino médio. As antigas disciplinas escolares não figuram nominalmente como elementos de organização curricular, não sendo veiculadas como portadoras de habilidades específicas a serem desenvolvidas. Assim, ainda que sejam percebidas como elementos que integram as áreas do conhecimento, não são componentes curriculares obrigatórios em todos os anos do Ensino Médio.

$\mathrm{Na}$ seção que apresenta a proposta dos itinerários formativos, mais uma vez advogando em favor da flexibilização curricular, o termo disciplina (escolar) volta a ser enunciado por meio de uma citação direta das Diretrizes Curriculares Nacionais, as quais indicam a necessidade de se romper com "a centralidade das disciplinas nos currículos e substituí-las por aspectos mais globalizadores e que abranjam a complexidade das relações 
existentes entre os ramos da ciência no mundo real" (BRASIL, 2013, p. 183 apud BRASIL, 2018, p. 471). É também notável que a Base Nacional Comum Curricular não apresente muitas referências às disciplinas escolares que, supostamente, compõem a área de Ciências da Natureza e suas Tecnologias. A primeira referência explícita aparece na página 33, junto a um esquema que segue apresentando a estrutura de organização curricular do ensino médio. Ao lado desse esquema, o seguinte trecho busca explicitar como áreas, disciplinas (sem citar o termo), competências e habilidades se articulam em meio ao currículo a ser estruturado:

As áreas de Ciências da Natureza e suas Tecnologias (Biologia, Física e Química), Ciências Humanas e Sociais Aplicadas (História, Geografia, Sociologia e Filosofia) e Matemática e suas Tecnologias (Matemática) seguem uma mesma estrutura: definição de competências específicas de área e habilidades que lhes correspondem. Na área de Linguagens e suas Tecnologias (Arte, Educação Física, Língua Inglesa e Língua Portuguesa), além da apresentação das competências específicas e suas habilidades, são definidas habilidades para Língua Portuguesa (BRASIL, 2018, p. 33).

Entendemos, então, que, nas reformas recentes para o ensino médio no país, as noções de áreas do conhecimento e disciplinas escolares têm as suas fronteiras 'borradas'. Afinal, apesar de a Base Nacional Comum Curricular sair em defesa de uma organização na qual as disciplinas escolares são escassamente nomeadas, os contornos em torno do que sejam as áreas do conhecimento e como estas se relacionam com as noções de competências e habilidades permanecem sendo produzidas em meio a sentidos de integração curricular que são regulados pelas regras e padrões da organização disciplinar.

Vale ressaltar que os conceitos de competências e habilidades vêm sendo enunciados desde a emergência das reformas aqui investigadas. Já nos Parâmetros Curriculares Nacionais para o ensino médio ambos emergem como elementos que atravessavam os sentidos associados às áreas do conhecimento e disciplinas escolares; neles, porém, a importância e centralidade dessas últimas era explícita, aspecto que se evidencia, por exemplo, no texto de apresentação da área de Ciências da Natureza, Matemática e suas Tecnologias:

Esta é uma proposta para o Ensino Médio, no que se relaciona às competências indicadas na Base Nacional Comum, correspondentes à área de Ciências da Natureza, Matemática e suas Tecnologias. Pretende, portanto, uma explicitação das habilidades básicas, das competências específicas, que se espera sejam desenvolvidas pelos alunos em Biologia, Física, Química e Matemática nesse nível escolar, em decorrência do aprendizado dessas disciplinas e das tecnologias a elas relacionadas (BRASIL, 1999, p. 4). 
Considerando a perspectiva aqui adotada, assumimos que esse deslocamento de sentidos no âmbito das reformas destinadas ao ensino médio, antes de produzirem antagonismos, indicam movimentos nos quais são construídas as 'verdades' dos currículos. Neles, as disciplinas escolares, que vinham sendo significadas como elementos relevantes na orientação das aprendizagens esperadas pelos estudantes ao final do ensino médio, vão sendo raramente enunciadas, estando submetidas às competências gerais de área, ainda que regulem o sistema por meio do qual continuamos a pensar e produzir a organização dos currículos. Uma evidência de tal regulação, como já explicitado, emerge no modo como a Língua Portuguesa e a Matemática, diferentemente dos outros componentes curriculares, permanecem estabilizadas no formato disciplinar, com habilidades explicitamente detalhadas. Ou seja, o que é considerado hierarquicamente mais importante parece estar mais fortemente regulado pelas regras e padrões que vieram, historicamente, constituindo os currículos escolares.

Por fim, parece-nos que os sentidos de integração curricular também vieram se deslocando nessas reformas curriculares, se afastando, de certo modo, da interdisciplinaridade como perspectiva hegemônica de preenchimento de tais significados. Afinal, enquanto nas comunidades disciplinares a integração curricular vinha sendo hegemonicamente significada como interdisciplinaridade (CHARRET, BRASIL \& FERREIRA, 2017 e 2018), em uma perspectiva que, de certo modo, mantinha estável o status das disciplinas escolares, na Base Nacional Comum Curricular ela se articula mais fortemente com as áreas do conhecimento, composta agora por elementos sem muitos contornos ou definições e que foram renomeados por meio de um novo significante, os componentes curriculares. De acordo com o referencial teórico aqui adotado, entendemos não ser possível analisar esse processo como uma mera renomeação das estruturas de organização curricular; afinal, “(...) palavras e coisas dizem respeito a fatos e enunciados, que a rigor são 'raros', isto é, não são óbvios, estão para além das 'coisas dadas"' (FISCHER, 2012, p. 100, grifos originais).

Entendemos, portanto, que, mais do que uma oposição, a aproximação entre o termo componentes curriculares e as tradicionais disciplinas escolares se faz em um embate produtivo entre o 'tradicional' e o 'novo', no qual se produz um sentido de reforma que a coloca no centro da superação de dilemas que assolam o ensino médio no país. Afinal,

O Ensino Médio é a etapa final da Educação Básica, direito público subjetivo de todo cidadão brasileiro. Todavia, a realidade educacional do 
País tem mostrado que essa etapa representa um gargalo na garantia do direito à educação. Entre os fatores que explicam esse cenário, destacam-se o desempenho insuficiente dos alunos nos anos finais do Ensino Fundamental, a organização curricular do Ensino Médio vigente, com excesso de componentes curriculares, e uma abordagem pedagógica distante das culturas juvenis e do mundo do trabalho (BRASIL, 2018, p. 461).

A citação anterior sugere um processo discursivo de construção de mais um par binário na retórica da reforma, uma vez que as disciplinas escolares, obrigatórias, fragmentadas e tradicionais, são ressignificadas no discurso atual como componentes curriculares, flexíveis, contextualizados e significativos. E é na noção de flexibilidade curricular que reside uma chave potente para o entendimento do deslocamento das disciplinas escolares em direção ao 'novo' significante componente curricular, compondo uma "nova estrutura [que] valoriza o protagonismo juvenil, uma vez que prevê a oferta de variados itinerários formativos para atender à multiplicidade de interesses dos estudantes: o aprofundamento acadêmico e a formação técnica profissional” (BRASIL, 2018, p. 467).

\section{CONSIDERAÇÕES FINAIS}

Ao investigar os sentidos de integração curricular que vêm sendo produzidos, disputados e fixados no tempo presente, focalizando as políticas para o ensino médio no Brasil e, em particular, para a área de Ciências da Natureza e suas Tecnologias, assumimos uma perspectiva teórica que toma a Base Nacional Comum Curricular, o texto curricular mais recente, como ponto de partida para uma investigação que percebe os acontecimentos históricos em estratos que se movimentam e se condensam. Partimos da centralidade que este documento assume no cenário reformista, tendo em vista tanto a referência que lhe é feita na Lei 13.415 (BRASIL, 2017), em seu artigo 35-A, que determina a Base Nacional Comum Curricular como a instância onde serão determinados os objetivos e a estrutura organizacional do ensino médio, quanto o seu caráter fortemente normativo, aspecto que a diferencia dos documentos orientadores dos currículos até então publicados. Além disso, nossa opção referese ao modo como vimos produzindo essa História do Currículo do Presente, tendo explícita motivação metodológica. Afinal, nossa intenção foi a de partir do momento presente, buscando nos ditos da Base Nacional Comum Curricular indícios que nos movem tanto para as experiências passadas quanto para as nossas projeções de futuro, com vistas a entender as 
condições que tornaram possível a estabilização provisória de certos discursos.

A ideia foi investigar os referidos sentidos tomando como referência um histórico e importante embate que se explicita e ganha força entre as áreas do conhecimento e as disciplinas escolares. Partindo do significado que a integração curricular veio assumindo no âmbito das comunidades disciplinares, qual seja, o de interdisciplinaridade (CHARRET \& FERREIRA, 2016, 2017a e 2017b; CHARRET, BRASIL \& FERREIRA, 2017 e 2018), vimos analisando os deslocamentos do discurso reformista na direção das áreas do conhecimento, ainda que regulado pelas regras e padrões da organização disciplinar. Nesse movimento, o termo disciplina escolar vai deixando de ser enunciado, em um movimento que desloca os sentidos de integração curricular no diálogo com os componentes curriculares, estes enunciados como mais flexíveis, contextualizados e significativos. As noções de competências e habilidades vieram se transformando em elementos de adjetivação do conhecimento disciplinarizado, produzindo efeitos no modo como passamos a pensar a 'validade' daquilo que ensinamos e aprendemos no ensino médio, assim como os nossos papéis como professores e estudantes nesse nível da educação básica.

Todo o processo aqui investigado tornou possível chamar a atenção para o modo como as políticas de currículo vieram sendo discursivamente produzidas no presente, em um movimento cíclico e muito mais complexo do que as explicações estadocêntricas têm nos possibilitado avançar. Argumentamos que esse modo de produzir uma História do Currículo do Presente, por meio de uma abordagem discursiva que, no diálogo com Michel Foucault, articula seus interlocutores no campo, têm nos permitido avançar nas críticas para além da simples denúncia. Afinal, ao assumir que a nomeação é um ato político, evidenciamos que a escolha dos significantes nunca é aleatória, mas preenchida de intencionalidades, regulando quem somos (e quem não somos) e o que podemos (ou não podemos) dizer. Nesse contexto, cabe a nós, investigadores das políticas em cenários reformistas, promover a proliferação de sentidos possíveis para os currículos na educação básica brasileira, conquistando novos interlocutores e gerando outros modos de re-existência em tempos tão difíceis e sombrios.

\section{REFERÊNCIAS}

BOWE, Richard; BALL, Stephen; GOLD, Anne. Reforming education and changing schools: case studies in Policy Sociology. Londres/Nova Iorque: Routledge, 1992. 
BRASIL. Ministério da Educação. Conselho Nacional de Educação. Câmara de Educação Básica. Resolução CEB no 3, de 26 de junho de 1998. Institui as Diretrizes Curriculares Nacionais para o Ensino Médio. Diário Oficial da União, Brasília, DF, 5 ago. 1998.

BRASIL. Ministério da Educação. Secretaria de Educação Média e Tecnológica. Parâmetros Curriculares Nacionais: Ensino Médio. Brasília: MEC/SEMTEC, 1999.

BRASIL. Ministério da Educação. Conselho Nacional de Educação. Conselho Pleno. Parecer CNE/CP no 11, de 30 de junho de 2009. Proposta de experiência curricular inovadora do Ensino Médio. Brasília: CNE/CP, 2009.

BRASIL. Ministério da Educação. Secretaria de Educação Básica. Programa Ensino Médio Inovador - Documento Orientador. Brasília: MEC/SEB, 2013.

BRASIL. Lei $\mathbf{n}^{\mathbf{0}} \mathbf{1 3 . 4 1 5}$, de 16 de fevereiro de 2017, Altera as Leis $\mathrm{n}^{\mathbf{0}}$ 9.394, de 20 de dezembro de 1996, que estabelece as diretrizes e bases da educação nacional, e 11.494, de 20 de junho 2007, que regulamenta o Fundo de Manutenção e Desenvolvimento da Educação Básica e de Valorização dos Profissionais da Educação, a Consolidação das Leis do Trabalho - CLT, aprovada pelo Decreto-Lei no 5.452 , de $1^{\circ}$ de maio de 1943, e o decreto-Lei $n^{\circ} 236$, de 28 de fevereiro de 1967; revoga a Lei $n^{0} 11.161$, de 5 de agosto de 2005; e institui a Política de Fomento à Implementação de Escolas de Ensino Médio em Tempo Integral. 2017.

BRASIL. Ministério da Educação. Secretaria de Educação Básica. Base Nacional Comum Curricular - Ensino Médio. MEC/SEB, 2018.

CHARRET, Heloize. Integração curricular nas reformas do ensino médio: estabilidade e mudança no embate entre as áreas de conhecimentos e as disciplinas escolares. Orientadora: Marcia Serra Ferreira. 2019. Tese (Doutorado em Educação). Universidade Federal do Rio de Janeiro, Rio de Janeiro, 2019.

CHARRET, Heloize; FERREIRA, Marcia Serra. Políticas de integração curricular no tempo presente: investigando a construção sociohistórica da área de Ciências da Natureza no ensino médio brasileiro. In: Memorias XII Congreso Iberoamericano de Historia de la Educación Latinoamericana (CIHELA). Medellin: Universidad de Antioquia, 2016, p. 1015-1027.

CHARRET, Heloize; FERREIRA, Marcia Serra. Políticas de Integração Curricular no tempo presente: perspectivas para a disciplina escolar Física no Ensino Médio Brasileiro. In: Anais do XXII Simpósio Nacional de Ensino de Física (SNEF), 2017a, p. 1-7.

CHARRET, Heloize; FERREIRA, Marcia Serra. Curriculum integration policies: investigating the sociohistorical teacher objectification processes in Brazilian high school education. In: AERA Annual Meeting, 2017, San Antonio. AERA Online Paper Repository. San Antonio: AERA, 2017b. p. 1-5.

CHARRET, Heloize; BRASIL, Gabriel; FERREIRA, Marcia Serra. Sentidos de integração curricular na comunidade disciplinar de Ciências da Natureza (2011-2015). In: Anais do XI 
Encontro Nacional de Pesquisa em Educação em Ciências (ENPEC). Florianópolis: ABRAPEC, 2017. p. 1-9.

CHARRET, Heloize; BRASIL, Gabriel; FERREIRA, Marcia Serra. Sentidos de integração curricular na área de Ciências da Natureza e o Novo Ensino Médio no Brasil: uma análise das políticas públicas entre 1998 e 2017. In: Anais do XIII Congreso Iberoamericano de Historia de la Educación Latinoamericana (CIHELA). Montevideo: SUHE, 2018, p. 1-10.

FERREIRA, Marcia Serra. A história da disciplina escolar Ciências no Colégio Pedro II (1960-1980). Orientador: Antonio Flavio Barbosa Moreira. 2005. Tese (Doutorado em Educação) - Universidade Federal do Rio de Janeiro, Rio de Janeiro, 2005.

FERREIRA, Marcia Serra. História do Currículo e das Disciplinas: apontamentos de pesquisa. In: FAVACHO, André Márcio Picanço; PACHECO, José Augusto; SALES, Shirlei Rezende (Orgs.). Currículo, conhecimento e avaliação: divergências e tensões. 1ed. Curitiba: CRV, 2013, p. 75-88.

FERREIRA, Marcia Serra. História do Currículo e das Disciplinas: produzindo uma abordagem discursiva para investigar a formação inicial de professores nas Ciências Biológicas. In: LEITE, Miriam; GABRIEL, Carmen Teresa (Orgs.). Linguagem, Discurso, Pesquisa e Educação. Petrópolis: De Petrus; Rio de Janeiro: FAPERJ, 2015, p. 265-284.

FERREIRA, Marcia Serra; SANTOS, André Vitor Fernandes dos. Discursos curriculares no/do tempo presente: subsídios para uma articulação entre a História e as Políticas de Currículo. In: LOPES, Alice Casimiro; OLIVEIRA, Marcia Betânia (Orgs.). Políticas de currículo: pesquisas e articulações discursivas. Curitiba: CRV, 2017. p. 55-78.

FISCHER, Rosa Maria Bueno. Trabalhar com Foucault: arqueologia de uma paixão. Belo Horizonte: Autêntica, 2012.

FOUCAULT, Michel. A arqueologia do saber. 8. ed. Rio de Janeiro: Forense Universitária, 2012a.

FOUCAULT, Michel. A ordem do discurso - aula inaugural no Collège de France. São Paulo: Edições Loyola, 2012b.

GOODSON, Ivor. Currículo: Teoria e História. Petrópolis: Vozes, 1995.

GOODSON, Ivor. A Construção Social do Currículo. Lisboa: Educa, 1997.

KOSELLECK, Reinhart. Futuro Passado: contribuição à semântica dos tempos históricos. Editora PUC-Rio, Contraponto 368p. 2006.

KOSELLECK, Reinhart. Estratos do tempo. Rio de Janeiro: Contratempo: PUC-Rio, 2014.

MAINARDES, Jefferson. Educação e Sociedade. Campinas, v. 27, n. 94, p. 47-69, jan./abr. 2006 
MOZENA, Erika Regina; OSTERMANN, Fernanda. Integração curricular por áreas com extinção das disciplinas no Ensino Médio: Uma preocupante realidade não respaldada pela pesquisa em Ensino de Física. Revista Brasileira de Ensino de Física, v. 36, n. 1, 2014.

POPKEWITZ, Thomas. História do currículo, regulação social e poder. In: SILVA, Tomaz Tadeu da (Org.). O sujeito da educação: estudos foucaultianos. 8. ed. Petrópolis, RJ: Vozes, 1994.

POPKEWITZ, Thomas. Reforma educacional: uma política sociológica - poder e conhecimento em educação. Porto Alegre: Artes Médicas, 1997.

POPKEWITZ, Thomas. Lutando em defesa da alma: a política do ensino e a construção do professor. Porto Alegre: Artmed, 2001.

SANTOS, André Vitor Fernandes dos. Regularidades discursivas sobre mudança curricular e a produção de subjetividades no Exame Nacional do Ensino Médio (Enem). Orientadora: Marcia Serra Ferreira Tese (Doutorado em Educação) - Universidade Federal do Rio de Janeiro, Rio de Janeiro, 2017.

\section{NOTA}

${ }^{1}$ Estamos nos referindo aos projetos de pesquisa Reformas em curso na formação de professores em Ciências Biológicas: significando a inovação curricular no tempo presente, Curriculum History: producing a discursive approach to researching curricular reforms in/of the present time e História do Currículo e das Disciplinas: desenvolvimento e uso de uma abordagem discursiva para investigações no ensino e na formação de professores, desenvolvidos com recursos do CNPq, da Comissão Fulbright e do CNE/Faperj.

Enviado em: 10/09/2019

Aprovado em: 04/11/2019 